\title{
CAS Number
}

National Cancer Institute

\section{Source}

National Cancer Institute. CAS Number. NCI Thesaurus. Code C54682.

A unique numerical identifier assigned, by the Chemical Abstract Service (CAS), a division

of the American Chemical Society, to chemical compounds, polymers, biological sequences, mixtures, and alloys. 